\title{
CARACTERIZAÇÃo FITOFISIONÔMICA E LEVANTAMENTO FLORÍSTICO PRE- LIMINAR NO PANTANAL DOS RIOS MORTES-ARAGUAIA, COCALINHO, MATO GROSSO, BRASIL ${ }^{1}$
}

\author{
Beatriz Schwantes Marimon ${ }^{2}$ \\ Edson de Souza Lima ${ }^{2,3}$
}

Recebido em 22/10/99. Aceito em 16/04/01

\begin{abstract}
RESUMO - (Caracterização fitofisionômica e levantamento florístico preliminar no Pantanal dos Rios MortesAraguaia, Cocalinho, MT, Brasil). O presente estudo realizou-se no Pantanal dos Rios Mortes-Araguaia, extensa planície inundável localizada no municípo de Cocalinho, nordeste de Mato Grosso, Brasil. Efetuou-se uma caracterização fitofisionômica e um levantamento florístico preliminar da região. Foram selecionados três Sítios, com fitofisionomias representativas: proximidades do Rio das Mortes ( $\left.12^{\circ} 37^{\prime} \mathrm{S} ; 5^{\circ} 55^{\prime} \mathrm{W}\right)$, foz do Rio das Mortes com o Araguaia ( $\left.11^{\circ} 54^{\prime} \mathrm{S} ; 50^{\circ} 48^{\prime} \mathrm{W}\right)$ e porção mediana do Rio Cristalino (12 $52^{\prime}$ S ; 50 $50^{\circ}$ ' W). O método de amostragem adotado foi o de levantamentos rápidos. Foram identificadas oito fitofisionomias: Mata Inundável, Caapão, Babaçual, Cerradão, Cerrado stricto sensu, Campo de Murunduns, Campo de Byrsonima orbignyana e Campo Cerrado de Vochysia rufa. Foram levantadas 248 espécies de árvores, arbustos, sub-arbustos e lianas, distribuídas em 158 gêneros e 62 famílias. As fitofisionomias apresentaram um padrão heterogêneo, sendo que nenhuma das espécies ocorreu em todas elas. Porém, Alibertia edulis (L. Rich.) A. Rich., Andira cuyabensis Benth., Maprounea guianensis (Aubl.) M. Arg., entre outras, ocorreram em seis das oito fitofisionomias. As famílias com maior riqueza foram: Caesalpiniaceae, Annonaceae e Myrtaceae. Ocorreram algumas semelhanças florísticas com o Pantanal do Rio Paraguai, porém, são necessários estudos mais aprofundados para confirmar. Os padrões de heterogeneidade fitofisionômica indicam que a área estudada necessita de medidas conservacionistas.
\end{abstract}

Palavras-chave - Brasil, Cerrado, Pantanal, Florística, Fitofisionomias.

\begin{abstract}
Vegetation types and preliminary floristic survey in the Mortes-Araguaia Pantanal, Cocalinho, Mato Grosso, Brazil). This study was carried out in the Pantanal of the Mortes and Araguaia rivers, a flooded plain located in Cocalinho, northeastern Mato Grosso, Brazil. The objectives of this study were to conduct a preliminary survey of the flora and to characterize the vegetation types. Three representative sites were selected: one near Rio das Mortes (12 ${ }^{\circ}$ $\left.37^{\prime} \mathrm{S} ; 50^{\circ} 55^{\prime} \mathrm{W}\right)$, one at the mouth of Araguaia and Mortes rivers $\left(11^{\circ} 54^{\prime} \mathrm{S} ; 50^{\circ} 48^{\prime} \mathrm{W}\right)$ and one in the middle portion of the Cristalino river (12 $52^{\prime}$ S; 50 $0^{\circ}$ ' ' W). Sampling was by the Rapid Survey method. Eight vegetation types were identified: Mata Inundável (swamp forest), Caapão (also swamp forest), Babaçual (Attalea speciosa forest), Cerradão, Cerrado stricto sensu (savanna types, closed canopy woodland and savanna grassland, respectively), Campo de Murunduns (grassland with scattered mounds bearing termites), Campo de Byrsonima orbignyana (grassland dominated
\end{abstract}

\footnotetext{
${ }^{1}$ Trabalho apresentado no $50^{\circ}$ Congresso Nacional de Botânica, Blumenau-SC, Julho/1999. Trabalhos de campo financiados pelo Instituto Pró-Natura, Rio de Janeiro, RJ, Brasil.

${ }^{2}$ Departamento de Ciências Biológicas, Campus Universitário de Nova Xavantina, UNEMAT, Caixa Postal 08, CEP 78.690000, Nova Xavantina, MT, Brasil. E-mail: biaben@zipmail.com.br.

${ }^{3}$ Mestrando em Ciências Florestais, Depto. de Engenharia Florestal, UnB, Brasília-DF.
} 
by B. orbignyana) and Campo Cerrado de Vochysia rufa (grassland with scattered trees of $V$. rufa). A total of 248 species of trees, shrubs and lianas were recorded, distributed in 158 genera and 62 families. The vegetation types were heterogeneous; none of the species occurred at all sites, but Alibertia edulis (L. Rich.) A. Rich., Andira cuyabensis Benth., Maprounea guianensis (Aubl.) M. Arg., and others, were found at six sites. The families richest in species were Caesalpiniaceae, Annonaceae and Myrtaceae. The flora apparently was similar to that of the Pantanal of Paraguai river, however, further studies are needed to confirm. This Heterogeneous vegetation patterns in the study area indicate the need to protect the Pantanal of the Mortes and Araguaia rivers.

Key words - Brazil, Savanna, Pantanal, Flora, Physiognomies.

\section{Introdução}

Em março de 1998 diversos especialistas (fauna, flora e meio físico) reuniram-se em Brasília-DF para propor Ações Prioritárias para a Conservação da Biodiversidade do Cerrado e Pantanal, baseando a urgência das ações de conservação, principalmente, nas pressões das atividades antrópicas e na vulnerabilidade natural das áreas analisadas. De acordo com o relatório elaborado pelos especialistas (MMA 1999), a região abrangida pela extensa planície, delimitada pelo Rio Araguaia e pelo Rio das Mortes no estado de Mato Grosso, mais conhecida como Pantanal dos Rios Mortes-Araguaia, foi classificada como área de importância biológica extremamente alta, com recomendação de ações voltadas para a criação de Unidades de Conservação e Manejo Sustentado.

A região vem sofrendo fortes pressões da agropecuária extensiva, do turismo indiscriminado (baseado principalmente na pesca predatória) e, mais recentemente, na possibilidade de implantação da Hidrovia Mortes-Araguaia-Tocantins, que poderá desencadear mudanças drásticas na paisagem regional. Assim, baseando-se na importância estratégica deste Pantanal, a FEMA (Fundação Estadual do Meio Ambiente) de Mato Grosso e o Instituto Pró-Natura do Rio de Janeiro, desencadearam um plano geral de estudos sócio-econômicos e ambientais visando a seleção de áreas potenciais para a implantação de uma ou mais Unidades de Conservação.
$\mathrm{O}$ presente estudo concentrou-se no município de Cocalinho, estado de Mato Grosso, abrangendo toda a porção cujos limites são, a oeste, o Rio das Mortes, a leste, o Rio Araguaia e ao sul, a rodovia MT-326 (Fig. 1).

A unidade geomorfológica característica da região é representada pela Depressão do Araguaia, desenvolvida sobre rochas do Pré-Cambriano Indiferenciado (Complexo Goiano), rochas Pré-Cambrianas do grupo Araxá e também uma grande extensão de cobertura dendrítico-laterítica e depósitos aluvionares e coluvionares pleistocênicos (RADAMBRASIL 1981). O relevo é plano, apresentando cotas altimétricas regulares entre 200 e $300 \mathrm{~m}$ e os solos predominantes são Laterita Hidromórfica Distrófica e Álica, com ocorrências esparsas de Latossolo VermelhoAmarelo Distrófico, Cambissolo Distrófico e Glei Pouco Húmico Distrófico, principalmente na área de influência direta dos rios (RADAMBRASIL 1981; PRODIAT 1984).

O clima da região estudada é tropical continental sempre quente com uma estação seca entre abril e setembro e uma chuvosa entre outubro e março (Camargo 1963) e, de acordo com Cochrane et al. (1985), do tipo $\mathrm{A}_{\mathrm{w}}$, segundo a classificação de Köppen. Dados dos últimos 30 anos, coletados na estação Meteorológica de Aragarças (cerca de 250km ao sul do Pantanal Mortes-Araguaia), apresentaram uma temperatura média anual de $24,9^{\circ} \mathrm{C}$, com temperaturas mínimas absolutas de $15^{\circ} \mathrm{C}$ e máximas de $33,7^{\circ} \mathrm{C}$ e precipitação média anual variando entre $1450 \mathrm{e}$ 1600mm (Nimer 1989). 

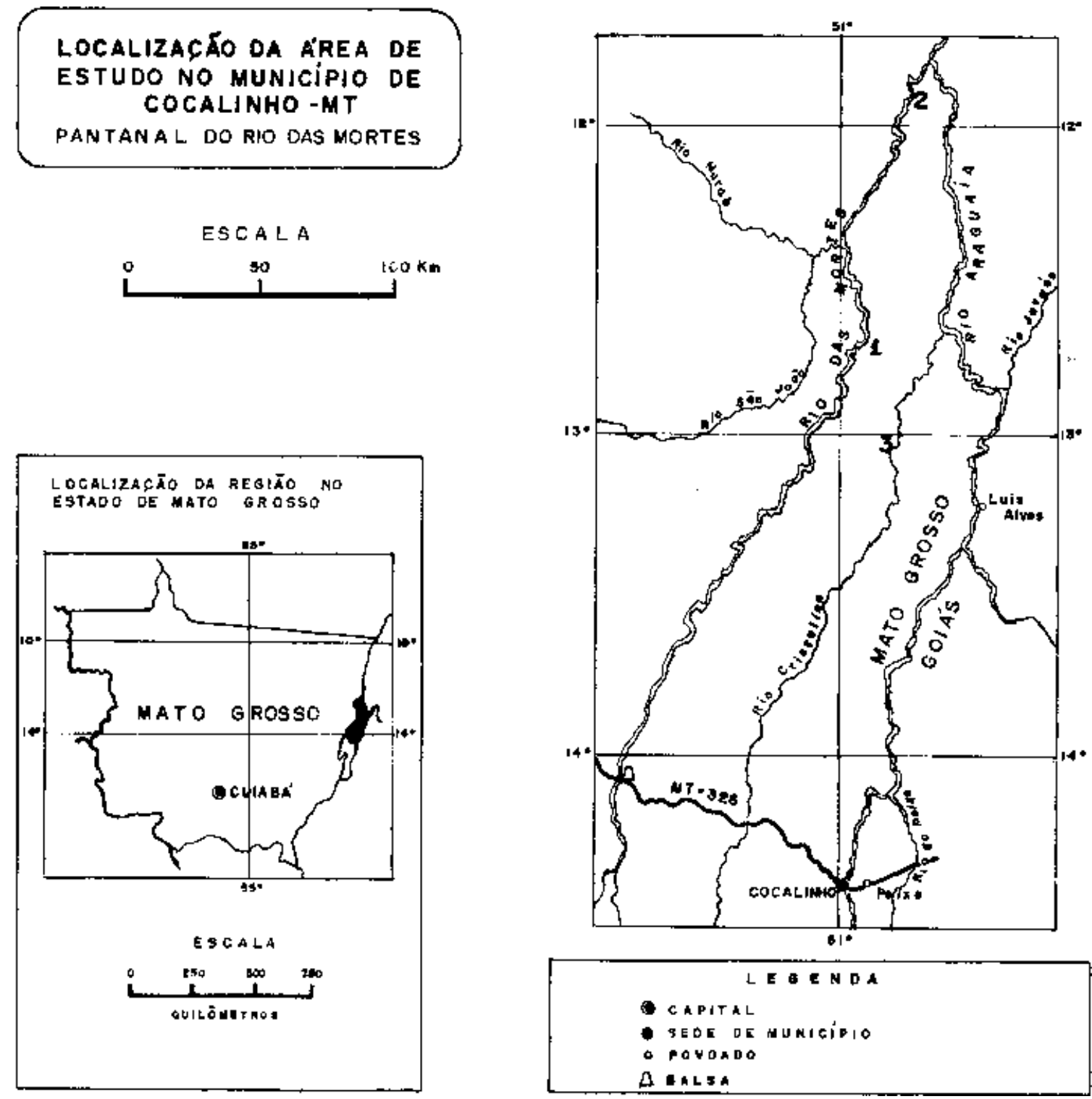

Figura 1. Localização geográfica da área de estudo e indicação dos Sítios 1, 2 e 3. Pantanal Mortes-Araguaia, Cocalinho-MT.

De acordo com RADAMBRASIL (1981), entre o Rio Araguaia e o Rio das Mortes, existe um padrão de drenagem onde se misturam rios paralelos entre si e rios anastomosados, atravessando trechos alternados de relevo conservado e dissecado da depressão. Na região, os rios Cristalino e Água Preta são os mais importantes neste padrão de drenagem.

Algumas fitofisionomias encontradas nesta planície foram caracterizadas e classi- ficadas por RADAMBRASIL (1981) como savana arbórea aberta e savana parque, com e sem floresta de galeria. A vegetação característica do Parque Nacional do Araguaia, localizado na Ilha do Bananal-TO e, portanto, próximo ao Pantanal Mortes-Araguaia, foi inicialmente estudada por IBDF (1981) e Ratter (1985). Os estudos do plano de manejo do Parque (IBDF 1981) identificaram a ocorrência de Cerrado, Cerradão, Mata Seca/ 
Transição, Mata Inundada, Campo Inundado, Mata Ciliar Inundada, Vegetação das encostas secas e Vegetação de bancos de areia. De acordo com Ratter (1987), o Parque situa-se na zona de contato entre o Cerrado e a Floresta Amazônica, apresenta extensas áreas de campos sazonalmente inundados (Campos de Murundu), complexos de Cerrado/ Cerradão, Mata Inundável, Mata Seca (Ratter et al. 1973) e uma pequena área de Mata Estacional Semidecídua (Ratter et al. 1978a), formando um verdadeiro mosaico vegetacional.

Castro (1997) estudou os efeitos da geomorfologia e do regime de inundação na estrutura de paisagem da vazante do Rio Araguaia e identificou tipos vegetacionais (Macega e Mata de Jaú-Embaúba) como os pioneiros associados a regiões de elevado stress provocado pela dinâmica do rio. Assim, as complexas e pouco conhecidas fitofisionomias que se inserem nesta planície de inundação necessitam de estudos detalhados, principalmente se considerarmos as importantes relações que ocorrem entre esta área inundável e a fauna regional (ex: berçário natural de peixes migratórios e abrigo de espécies amazônicas características de ambientes lênticos, Prof. Dr. César Enrique de Melo, com. pessoal).

O objetivo deste trabalho foi contribuir para o conhecimento da flora do Pantanal Mortes-Araguaia, através da elaboração de uma lista florística preliminar e da caracterização fitofisionômica, contribuindo com um referencial inicial da flora fanerogâmica do município de Cocalinho-MT. A caracterização deste Pantanal, ainda pouco conhecido, contribuirá na identificação de padrões de heterogeneidade florística e fitofisionômicas, garantindo a seleção de áreas ótimas para implantação de Unidade(s) de Conservação.

\section{Material e métodos}

A partir de um sobrevôo prévio na área delimitada pelos Rios Araguaia e das Mortes e pela rodovia MT-326 (entre as coordenadas $\left.11^{\circ} 30^{\prime} / 14^{\circ} 00^{\prime} \mathrm{S} ; 5^{\circ} 30^{\prime} / 50^{\circ} 30^{\prime} \mathrm{W}\right)$ e análise de imagens de satélite, selecionaram-se três $\underline{\text { Sítios }}$ para o desenvolvimento dos trabalhos de campo, os quais foram delimitados a partir do menor grau de antropização e maior representatividade fitofisionômica. O Sítio 1 localiza-se na margem direita do Rio das Mortes (12 $\left.37^{\prime} \mathrm{S} ; 50^{\circ} 55^{\prime} \mathrm{W}\right)$ na Fazenda Água Bela e arredores. O Sítio 2 encontra-se na Fazenda Porto do Sol e arredores (11 $1^{\circ} 54^{\prime} S$; $50^{\circ} 48^{\prime} \mathrm{W}$ ), abrangendo a foz do Rio das Mortes com o Araguaia e, o Sítio 3 está localizado na margem esquerda do Rio Cristalino (12 $\left.52^{\prime} \mathrm{S} ; 50^{\circ} 49^{\prime} \mathrm{W}\right)$, cerca de $60 \mathrm{~km}$ ao sul de sua foz, na Fazenda Santa Cruz do Cristalino e áreas próximas (Fig. 1). Os trabalhos de campo desenvolveram-se durante 16 dias contínuos, tendo sido utilizados aproximadamente quatro dias por sítio.

O levantamento baseou-se na seleção das fitofisionomias representativas de cada sítio e na delimitação de oito Pontos de Observação (PO) aleatórios em cada fitofisionomia. Em cada PO foi efetuado o levantamento de todas as espécies lenhosas observadas no decorrer de uma caminhada de uma hora. O tempo foi dividido em blocos de 15 minutos, durante os quais foram identificadas todas as espécies novas encontradas. Optou-se por este sistema de blocos visando alcançar o achatamento da curva espécies-tempo e garantir uma amostragem satisfatória. Se, após o quarto bloco consecutivo de 15 minutos, o número de espécies novas tivesse aumentado, utilizavam-se 15 minutos (ou mais) adicionais até atingir a estabilização da curva. A caminhada foi sempre efetuada em um ritmo regular, baseando-se no método de levantamentos rápidos (Rapid Survey) adotado no projeto Biodiversidade do Bioma Cerrado, 
Embrapa/DFID/UnB (J. A. Ratter, com. pes.). Durante a coleta e/ou observação mais detalhada de uma espécie, a cronometragem era interrompida para não alterar o esforço amostral entre os blocos de 15 minutos.

As espécies foram classificadas de acordo com a abundância nas fitofisionomias, sendo $\mathrm{A}=$ abundante (espécie predominante em todos PO's), $\mathrm{C}=$ comum (encontrada em todos os PO's sem ser predominante), $\mathrm{F}=$ freqüente (encontrada em mais de $50 \%$ dos PO's), $\mathrm{O}=$ ocasional (esporadicamente encontrada) e $\mathrm{R}=$ rara (só uma vez ou raramente encontrada) (Sobrevila \& Bath 1992). Baseando-se no que foi proposto por Mori et al. (1989), cada espécie também foi classificada de acordo com o hábito, sendo árvore, arbusto, sub-arbusto ou liana.

Em cada fitofisionomia foram anotadas informações gerais que subsidiaram a caracterização das mesmas. As informações coletadas basearam-se no método de Avaliação Ecológica Rápida para a América Latina e Caribe (Sobrevila \& Bath 1992). Nesta etapa, os dados coletados foram: descrição geral da fitofisionomia, evidências de ameaça, uso geral da terra, macro-topografia, relevo, umidade, rochosidade, drenagem, erosão, textura e cor do solo, e aspectos gerais da estrutura da vegetação.

Foram efetuadas coletas de todas as espécies que apresentavam-se férteis, observadas no decorrer dos trabalhos de campo. A amostragem das espécies estéreis ocorreu mediante identificação in loco. As coletas foram incorporadas ao herbário da Coleção Zoobotânica James Alexander Ratter do Campus Universitário de Nova Xavantina/ UNEMAT. A identificação foi realizada através de comparações no Herbário UB (Universidade de Brasília), consultas a bibliografias especializadas e especialistas, quando necessário.

\section{Resultados e discussão}

Nos sítios estudados foram identificadas as seguintes fitofisionomias: Mata Inundável (111 espécies), Caapão (36), Babaçual (48), Cerradão (60), Cerrado stricto sensu (124), Campo de Murunduns (95), Campo Cerrado de Vochysia rufa (36) e Campo de Byrsonima orbignyana (1). O Babaçual, ocorreu somente no Sítio 3 e as demais fitofisionomias ocorreram nos três sítios.

Ratter (1987), efetuando um levantamento no Parque Nacional do Araguaia, identificou seis fitofisionomias e neste caso, as coincidências ocorreram para o Cerradão, Mata Inundável e Campo de Murunduns. O referido autor apresentou 105 espécies de árvores e arbustos que ocorreram no Complexo Cerrado/Cerradão Distrófico, sendo portanto, superior ao número de espécies encontradas no Cerradão e inferior ao número de espécies do Cerrado s.s., do presente estudo. Para a Mata Inundável, Ratter (1987) encontrou 23 espécies e para o Campo de Murunduns, apenas 63. Estes aspectos ressaltam a necessidade de se efetuar estudos individualizados em cada região, principalmente se considerarmos o verdadeiro mosaico de fitofisionomias existente no bioma Cerrado (Ratter et al. 1973, Eiten 1979).

Na Tabela 1 foram listados 248 táxons distribuídos em 158 gêneros e 62 famílias, levantados em sete dentre as oito fitofisionomias estudadas (o Campo de Byrsonima orbignyana não foi incluído por apresentar apenas uma espécie lenhosa). Destes, 90,5\% foram identificados a nível de espécie, $9 \%$ a nível de gênero e $0,5 \%$ apenas a nível de família. Observou-se ainda que 53,2\% são árvores, $23 \%$ arbustos, $5,7 \%$ sub-arbustos, $4 \%$ lianas e $14,1 \%$ das espécies estiveram representadas, em algumas fitofisionomias, como árvores e em outras atingiram apenas o porte de arbusto ou então, em algumas como arbusto e em outras como sub-arbusto. 
A família de maior riqueza foi Caesalpiniaceae com 16 espécies, seguida por Annonaceae e Myrtaceae com 11 espécies cada e, Arecaceae, Euphorbiaceae, Fabaceae e Rubiaceae com 10 espécies cada, representando cerca de $31 \%$ de todas as espécies levantadas e $33 \%$ dos gêneros. Ratter (1987) também apresentou estas famílias em posições similares, em termos de riqueza de espécies. Felfili (1994), para uma mata de galeria do Distrito Federal e Oliveira-Filho (1989), para uma mata de galeria de Mato Grosso, indicaram posições de destaque para Caesalpiniaceae.

O gênero Eugenia apresentou o maior número de espécies, sete, e só não ocorreu em áreas de Caapão, e o gênero Byrsonima, com seis espécies, ocorreu em todas as fitofisionomias. Este aspecto é relevante pois são espécies que produzem frutos potencialmente importantes para a fauna silvestre.

Dentre as espécies mais frequientes estão Alibertia edulis, Andira cuyabensis, Maprounea guianensis, Byrsonima orbignyana e Caryocar sp., que ocorreram em seis das oito fitofisionomias estudadas. Dentre as espécies levantadas, 101 (41\%) ocorreram em apenas uma fitofisionomia.

Observou-se que Calophyllum brasiliense, Vochysia divergens, Panopsis rubescens, Rheedia brasiliense, Sclerolobium froesii, Ternstroemia candolleana, entre outras, ocorreram em todos os ambientes de Mata Inundável e Caapão, tendo o mesmo sido observado por Ratter (1987) e, $C$. brasiliense também ocorreu em ambientes similares na região central do Brasil (Felfili 1995). Nascimento \& Cunha (1989) e Pott \& Pott (1994) observaram que $V$. divergens ocorre em áreas alagáveis do Pantanal do Rio Paraguai-MT/MS. Com relação aos ambientes típicos de Cerrado, Qualea parviflora, Copaifera martii, Couepia grandiflora, Curatella americana, Alibertia sessilis, Emmotum nitens, entre outros, ocorreram em todos eles. Dentre estas espécies, $C$. americana e $Q$. parviflora foram avaliadas por Ratter et al. (1996) para 98 áreas de Cerrado s.s., para as quais obtiveram 71 e $60 \%$ de ocorrência, respectivamente.

$\mathrm{Na}$ seqüência, serão descritas as características gerais das oito fitofisionomias estudadas sendo que, a Tabela 1 apresenta uma listagem, o hábito e a respectiva abundância das principais espécies lenhosas que nelas ocorreram.

Cerrado stricto sensu - a vegetação de Cerrado e a análise de sua composição florística tem sido extensivamente estudada e comparada em termos de sua localização geográfica (Eiten 1972; Ratter et al. 1996). O cerrado stricto sensu (s.s.) ocupa cerca de $70 \%$ da área total do Cerrado brasileiro, é composto por um estrato contínuo de gramíneas e outro de vegetação lenhosa de porte arbóreo e arbustivo, cobrindo cerca de $50 \%$ da superfície do solo (Eiten 1976).

O cerrado s.s., observado neste estudo, localiza-se em extensas áreas de planície, com relevo plano (0-4\% de declividade), solos de boa drenagem e ausência de erosão e rochosidade. Os solos predominantes são do tipo Latossolo Vermelho-Amarelo, profundos e com textura areno-argilosa.

Foram observados dois estratos bem definidos (um arbóreo e um arbustivo-herbáceo), com baixa densidade de árvores entre 10 e $15 \mathrm{~m}$ de altura e média a alta densidade de indivíduos com alturas inferiores a $5 \mathrm{~m}$. Dentre as espécies dominantes do estrato arbóreo, encontraram-se: Qualea parviflora, Byrsonima coccolobifolia, Andira cuyabensis, Pouteria ramiflora, Curatella americana, Salvertia convallariodora, Tabebuia aurea e Mouriri elliptica. O estrato arbustivo foi caracterizado pela presença de Davilla elliptica, Himatanthus obovatus e Annona dioica.

Ocasionalmente, as áreas de cerrado s.s. encontraram-se separadas das Matas 
Tabela 1. Lista das famílias e espécies lenhosas encontradas no Pantanal Mortes-Araguaia, Cocalinho-MT, associadas às fitofisionomias: Campo Cerrado de Vochysia rufa (CC), Campo de Murunduns (CM), Cerrado stricto sensu (CE), Cerradão (CO), Babaçual (BA), Caapões (CA) e Mata Inundável (MI). As espécies foram classificadas de acordo com o hábito: Árvore (A), Arbusto (Ar), Sub-Arbusto (Sa) e Liana (L) e, abundância nas respectivas fitofisionomias: Abundante (A), Comum (C), Freqüente $(\mathrm{F})$, Ocasional $(\mathrm{O})$ e Rara $(\mathrm{R})$.

\begin{tabular}{|c|c|c|c|c|c|c|c|}
\hline Famílias/Espécies & $\mathrm{CC}$ & $\mathrm{CM}$ & $\mathrm{CE}$ & $\mathrm{CO}$ & BA & $\mathrm{CA}$ & MI \\
\hline \multicolumn{8}{|l|}{ 1. Anacardiaceae } \\
\hline 1. Anacardium humile St. Hil. & & $\mathrm{Sa}(\mathrm{O})$ & $\mathrm{Sa}(\mathrm{F})$ & & & & \\
\hline 2. A. occidentale $\mathrm{L}$. & & $\operatorname{Ar}(\mathrm{O})$ & $\operatorname{Ar}(\mathrm{O})$ & & & & \\
\hline 3. Astronium fraxinifolium Schott. & & $\mathrm{A}(\mathrm{O})$ & $\mathrm{A}(\mathrm{O})$ & & & & $A(R)$ \\
\hline 4. Tapirira guianensis Aubl. & & & & & $\mathrm{A}(\mathrm{O})$ & & $\mathrm{A}(\mathrm{O})$ \\
\hline \multicolumn{8}{|l|}{ 2. Annonaceae } \\
\hline 5. Annona coriacea Mart. & $\operatorname{Ar}(\mathrm{F})$ & $\operatorname{Ar}(\mathrm{F})$ & $\operatorname{Ar}(\mathrm{O})$ & & & & \\
\hline 6. A. dioica St. Hil. & & $\operatorname{Ar}(\mathrm{O})$ & $\operatorname{Ar}(\mathrm{F})$ & & & & \\
\hline 7. A. tomentosa R. E. Fries & & $\operatorname{Ar}(\mathrm{F})$ & & & & & \\
\hline 8. Annona $\mathrm{sp}$. & & $\operatorname{Ar}(\mathrm{F})$ & $\operatorname{Ar}(\mathrm{R})$ & & & & \\
\hline 9. Cardiopetalum calophyllum Schltdl. & & & $\operatorname{Ar}(\mathrm{R})$ & & & & \\
\hline 10. Duguetia furfuracea (St. Hil.) Benth. \& Hook. f. & & & $\mathrm{Sa}(\mathrm{O})$ & & & & \\
\hline 11. D. marcgraviana Mart. & & & & & $\operatorname{Ar}(\mathrm{O})$ & & $\mathrm{A}(\mathrm{F})$ \\
\hline 12. Unonopsis lindmanii R. E. Fries & & & & & & & $\mathrm{A}(\mathrm{O})$ \\
\hline 13. Xylopia aromatica (Lam.) Mart. & & $\operatorname{Ar}(\mathrm{O})$ & $\mathrm{A}(\mathrm{O})$ & $\mathrm{A}(\mathrm{O})$ & $A(R)$ & & \\
\hline 14. X. sericea A. St. Hil. & & & & & $\mathrm{A}(\mathrm{O})$ & & $\mathrm{A}(\mathrm{F})$ \\
\hline 15. Xylopia sp. & & & & & & $\operatorname{Ar}(\mathrm{O})$ & $\operatorname{Ar}(\mathrm{O})$ \\
\hline \multicolumn{8}{|l|}{ 3. Apocynaceae } \\
\hline 16. Aspidosperma macrocarpon Mart. & & & $\mathrm{A}(\mathrm{O})$ & & & & \\
\hline 17. A. multiflorum A. DC. & & $\operatorname{Ar}(\mathrm{R})$ & $\mathrm{A}(\mathrm{O})$ & & & & \\
\hline 18. A. nobile Muell.-Arg. & & A (R) & & & & & \\
\hline 19. A. tomentosum Mart. & & & $\mathrm{A}(\mathrm{O})$ & & & & \\
\hline 20. Hancornia speciosa Gomes & & A (R) & A (F) & & & & \\
\hline 21. Himatanthus bracteatus (A. DC.) Woods. & & & & $\mathrm{A}(\mathrm{O})$ & & & \\
\hline 22. H. obovatus (Muell.-Arg.) Woods. & $\operatorname{Ar}(\mathrm{R})$ & $\operatorname{Ar}(\mathrm{O})$ & $\operatorname{Ar}(\mathrm{F})$ & & & & \\
\hline 23. Odontadenia lutea (Vell.) Markgr. & & $\mathrm{L}(\mathrm{R})$ & & & & & \\
\hline \multicolumn{8}{|l|}{ 4. Araliaceae } \\
\hline 24. Schefflera morototoni (Aubl.) Maguire, Steyerm \& Frodin & & & & $A(R)$ & & & \\
\hline \multicolumn{8}{|l|}{ 5. Arecaceae } \\
\hline 25. Allagoptera leucocalyx (Mart.) Kuntze & & $\mathrm{Sa}(\mathrm{O})$ & $\operatorname{Ar}(\mathrm{R})$ & & $\mathrm{Sa}(\mathrm{F})$ & & \\
\hline 26. Astrocaryum vulgare Mart. & & & $\operatorname{Ar}(\mathrm{O})$ & & $\operatorname{Ar}(\mathrm{O})$ & $\operatorname{Ar}(\mathrm{O})$ & $\operatorname{Ar}(\mathrm{C})$ \\
\hline 27. Attalea eichleri (Drude) Henderson & & $\operatorname{Ar}(\mathrm{F})$ & $\operatorname{Ar}(\mathrm{F})$ & & & & \\
\hline 28. A. speciosa Mart. ex Spreng. & & & & & $\mathrm{A}(\mathrm{A})$ & & \\
\hline 29. Bactris glaucescens Drude & & & & & & & $\operatorname{Ar}(\mathrm{F})$ \\
\hline 30. Desmoncus cf. cuyabensis Barb. Rodr. & & & & & & & $\mathrm{L}(\mathrm{O})$ \\
\hline 31. Mauritia flexuosa $\mathrm{L}$. & & & & & & & $A(R)$ \\
\hline 32. Mauritiella armata (Mart.) Burret & & A (R) & & & & A (R) & \\
\hline 33. Syagrus comosa (Mart.) Mart. & $\operatorname{Ar}(\mathrm{R})$ & $\operatorname{Ar}(\mathrm{F})$ & $\operatorname{Ar}(\mathrm{O})$ & & & & \\
\hline 34. S. flexuosa (Mart.) Becc. & & $\operatorname{Ar}(\mathrm{O})$ & $\operatorname{Ar}(\mathrm{O})$ & & & & \\
\hline \multicolumn{8}{|l|}{ 6. Bignoniaceae } \\
\hline 35. Arrabidaea corallina (Jacq.) Sandw. & & $\mathrm{L}(\mathrm{O})$ & & & & & $\mathrm{L}(\mathrm{R})$ \\
\hline 36. Jacaranda brasiliana (Lam.) Pers. & & $\mathrm{A}(\mathrm{O})$ & $\mathrm{A}(\mathrm{R})$ & & & & \\
\hline 37. Tabebuia aurea (Manso) Benth. \& Hook. & $\mathrm{A}(\mathrm{R})$ & $\mathrm{A}(\mathrm{C})$ & A (F) & & $\operatorname{Ar}(\mathrm{R})$ & & \\
\hline 38. T. impetiginosa (Mart. ex A. DC.) Standl. & & & A (R) & $\mathrm{A}(\mathrm{O})$ & & & \\
\hline 39. T. ochracea (Cham.) Standl. & & & $\mathrm{A}(\mathrm{O})$ & & & & \\
\hline 40. T. serratifolia (Vahl) Nicholson & & & & & & & $\mathrm{A}(\mathrm{O})$ \\
\hline \multicolumn{8}{|l|}{ 7. Bombacaceae } \\
\hline 41. Eriotheca gracilipes (K. Schum.) A. Robyns & & & $\mathrm{A}(\mathrm{O})$ & & & & \\
\hline 42. Pseudobombax longiflorum (Mart. \& Zucc.) A. Robyns & & $\operatorname{Ar}(\mathrm{O})$ & A (R) & & & & \\
\hline \multicolumn{8}{|l|}{ 8. Boraginaceae } \\
\hline 43. Cordia glabrata (Mart.) A. DC. & & $\mathrm{A}(\mathrm{O})$ & & & $\mathrm{A}(\mathrm{O})$ & & \\
\hline 44. C. sellowiana Cham. & & & & & & & $\mathrm{A}(\mathrm{O})$ \\
\hline \multicolumn{8}{|l|}{ 9. Burseraceae } \\
\hline 45. Protium heptaphyllum (Aubl.) E. K. Marchal & & $\mathrm{A}(\mathrm{O})$ & $\operatorname{Ar}(\mathrm{R})$ & A (F) & $\mathrm{A}(\mathrm{O})$ & & $\mathrm{A}(\mathrm{F})$ \\
\hline
\end{tabular}




\begin{tabular}{|c|c|c|c|c|c|c|c|}
\hline Famílias/Espécies (continuação tabela 1.) & $\mathrm{CC}$ & $\mathrm{CM}$ & $\mathrm{CE}$ & $\mathrm{CO}$ & $\mathrm{BA}$ & $\mathrm{CA}$ & MI \\
\hline 46. P. unifoliolatum (Spruce) Engl. & & & & $\operatorname{Ar}(\mathrm{F})$ & $\mathrm{A}(\mathrm{O})$ & & \\
\hline 47. Protium sp. & & $\mathrm{Sa}(\mathrm{F})$ & & & & & \\
\hline \multicolumn{8}{|l|}{ 10. Caesalpiniaceae } \\
\hline 48. Apuleia leiocarpa (Vog.) Macbr. & & & & $\mathrm{A}(\mathrm{R})$ & & & $\mathrm{A}(\mathrm{O})$ \\
\hline 49. Bauhinia rufa (Bong.) Steud. & $\mathrm{Sa}(\mathrm{O})$ & $\mathrm{Sa}(\mathrm{C})$ & $\mathrm{Sa}(\mathrm{O})$ & & & & \\
\hline 50. Cenostigma macrophyllum Tul. & & & $\mathrm{Sa}(\mathrm{C})$ & $\operatorname{Ar}(\mathrm{F})$ & & & \\
\hline 51. Chamaecrista $\mathrm{sp}$. & & & $\mathrm{Sa}(\mathrm{O})$ & & & & \\
\hline 52. Copaifera langsdorfii Desf. & & & $\operatorname{Ar}(\mathrm{R})$ & $\mathrm{A}(\mathrm{O})$ & $A(R)$ & & \\
\hline 53. C. martii Hayne & $\mathrm{Sa}(\mathrm{O})$ & $\mathrm{Sa}(\mathrm{C})$ & $\mathrm{Sa}(\mathrm{F})$ & $\mathrm{Sa}(\mathrm{C})$ & & & \\
\hline 54. Dimorphandra mollis Benth. & & & $\operatorname{Ar}(\mathrm{R})$ & & & & \\
\hline 55. Hymenaea courbaril L. & & & & & $A(R)$ & & \\
\hline 56. H. stigonocarpa Mart. ex Hayne & $\mathrm{A}(\mathrm{R})$ & & $\mathrm{A}(\mathrm{F})$ & & & & \\
\hline 57. Macrolobium bifolium (Aubl.) Pers. & & & & & & & $\mathrm{A}(\mathrm{F})$ \\
\hline 58. Peltogyne confertiflora (Hayne) Benth. & & & $\mathrm{A}(\mathrm{O})$ & & & & \\
\hline 59. Sclerolobium aureum (Tul.) Benth. & A (R) & $A(R)$ & $\mathrm{A}(\mathrm{O})$ & & & & \\
\hline 60. S. chrysophyllum Poepp. \& Endl. & & & & & & & $\mathrm{A}(\mathrm{F})$ \\
\hline 61. S. froesii Pires & & & & & & $\mathrm{A}(\mathrm{C})$ & $A(F)$ \\
\hline 62. S. paniculatum Vogel & & & $\mathrm{A}(\mathrm{F})$ & $\mathrm{A}(\mathrm{C})$ & & & \\
\hline \multirow{2}{*}{\multicolumn{8}{|c|}{ 11. Caryocaraceae }} \\
\hline & & & & & & & \\
\hline 64. Caryocar brasiliense Camb. & & & $\mathrm{A}(\mathrm{F})$ & & & & \\
\hline 65. Caryocar sp. & $\mathrm{A}(\mathrm{R})$ & $\mathrm{A}(\mathrm{O})$ & $\mathrm{A}(\mathrm{F})$ & $\mathrm{A}(\mathrm{C})$ & $\mathrm{A}(\mathrm{O})$ & & $A(R)$ \\
\hline \multicolumn{8}{|l|}{ 12. Cecropiaceae } \\
\hline 66. Cecropia pachystachya Tréc. & & & $A(R)$ & & $A(R)$ & & $\mathrm{A}(\mathrm{O})$ \\
\hline 67. C. palmata Willd. & & $\operatorname{Ar}(\mathrm{R})$ & & & & & $\mathrm{A}(\mathrm{C})$ \\
\hline \multicolumn{8}{|l|}{ 13. Chrysobalanaceae } \\
\hline $\begin{array}{l}\text { 68. Couepia grandiflora (Mart. \& Zucc.) Benth. ex Hook. } \\
\text { 69. Couepia sp. }\end{array}$ & $A(R)$ & $\mathrm{A}(\mathrm{O})$ & $\mathrm{A}(\mathrm{F})$ & $\mathrm{A}(\mathrm{F})$ & & & $\operatorname{Ar}(\mathrm{O})$ \\
\hline 70. Hirtella glandulosa Spreng. & & & $\mathrm{A}(\mathrm{R})$ & $\mathrm{A}(\mathrm{C})$ & & & \\
\hline 71. H. gracilipes (Hook. f.) Prance & & & $A(R)$ & & $\mathrm{A}(\mathrm{O})$ & $\operatorname{Ar}(\mathrm{O})$ & \\
\hline 72. Licania apetala (E. Meyer) Fritsch & & & & & & & $\mathrm{A}(\mathrm{C})$ \\
\hline 73. L. cf. kunthiana Hook. f. & & & & & & & $\mathrm{A}(\mathrm{O})$ \\
\hline 74. L. cf. parvifolia Huber & & & & & & $\mathrm{A}(\mathrm{C})$ & \\
\hline 75. L. gardneri (Hook. f.) Fritsch & $\operatorname{Ar}(\mathrm{R})$ & & $\mathrm{A}(\mathrm{O})$ & A (F) & $\mathrm{A}(\mathrm{F})$ & & $\mathrm{A}(\mathrm{O})$ \\
\hline \multicolumn{8}{|l|}{ 14. Clusiaceae } \\
\hline 76. Calophyllum brasiliense Camb. & & & & $\mathrm{A}(\mathrm{R})$ & $\mathrm{A}(\mathrm{O})$ & $\mathrm{A}(\mathrm{O})$ & A (A) \\
\hline 77. Caraipa densifolia Mart. & & & & & & $\mathrm{A}(\mathrm{O})$ & $A(R)$ \\
\hline 78. Kielmeyera rubriflora A. St.-Hil. & & & $\operatorname{Ar}(\mathrm{O})$ & & & & \\
\hline 79. K. speciosa A. St.-Hil. & & & $\operatorname{Ar}(\mathrm{R})$ & & & & \\
\hline 80. Rheedia brasiliense (Mart.) Planch. \& Triana & & & & & & $A(R)$ & $\mathrm{A}(\mathrm{F})$ \\
\hline \multicolumn{8}{|l|}{ 15. Cochlospermaceae } \\
\hline 81. Cochlospermum regium (Schrank) Pilg. & & $\mathrm{Sa}(\mathrm{R})$ & $\operatorname{Ar}(\mathrm{O})$ & & & & \\
\hline \multicolumn{8}{|l|}{ 16. Combretaceae } \\
\hline 82. Buchenavia capitata (Vahl.) Eichl. & & & & & & & $A(R)$ \\
\hline 83. B. tomentosa Eichl. & $\mathrm{A}(\mathrm{R})$ & $A(R)$ & $\mathrm{A}(\mathrm{F})$ & & $A(R)$ & $\mathrm{A}(\mathrm{R})$ & \\
\hline 84. Terminalia argentea Mart. \& Zucc. & & & $\mathrm{A}(\mathrm{O})$ & & & & \\
\hline \multirow{2}{*}{\multicolumn{8}{|c|}{ 17. Connaraceae }} \\
\hline & & & & & & & \\
\hline 86. Connarus suberosus Planch. & & $\operatorname{Ar}(\mathrm{O})$ & $\mathrm{A}(\mathrm{O})$ & & & & \\
\hline 87. Rourea induta Planch. & & $\operatorname{Ar}(\mathrm{F})$ & $\operatorname{Ar}(\mathrm{O})$ & & & & \\
\hline \multicolumn{8}{|l|}{ 18. Dichapetalaceae } \\
\hline 88. Tapura amazonica Poepp. \& Endl. & & & & $\mathrm{A}(\mathrm{O})$ & & & \\
\hline \multicolumn{8}{|l|}{ 19. Dilleniaceae } \\
\hline 89. Curatella americana $\mathrm{L}$. & $\mathrm{A}(\mathrm{O})$ & $\mathrm{A}(\mathrm{C})$ & $\mathrm{A}(\mathrm{F})$ & $\mathrm{A}(\mathrm{O})$ & & & \\
\hline 90. Davilla elliptica St. Hil. & & $\operatorname{Ar}(\mathrm{O})$ & $\operatorname{Ar}(\mathrm{F})$ & & & & \\
\hline 91. D. nitida (Vahl.) Kubitzki & & $\mathrm{L}(\mathrm{O})$ & $\mathrm{L}(\mathrm{O})$ & & & & $\mathrm{L}(\mathrm{O})$ \\
\hline 92. Doliocarpus dentatus (Aubl.) Standl. & & $\mathrm{L}(\mathrm{O})$ & & & & & $\mathrm{L}(\mathrm{O})$ \\
\hline \multicolumn{8}{|l|}{ 20. Ebenaceae } \\
\hline 93. Diospyros hispida DC. & $A(R)$ & $\mathrm{A}(\mathrm{O})$ & $\mathrm{A}(\mathrm{F})$ & $\mathrm{A}(\mathrm{O})$ & $\mathrm{A}(\mathrm{O})$ & & \\
\hline 94. D. obovata Jacq. & & & & & & $\mathrm{A}(\mathrm{F})$ & $\mathrm{A}(\mathrm{C})$ \\
\hline 95. D. sericea DC. & & & & $\mathrm{A}(\mathrm{O})$ & & & \\
\hline \multicolumn{8}{|l|}{ 21. Elaeocarpaceae } \\
\hline 96. Sloanea eichleri $\mathrm{K}$. Schum. & & & & & & & $A(R)$ \\
\hline
\end{tabular}




\begin{tabular}{|c|c|c|c|c|c|c|c|}
\hline Famílias/Espécies (continuação tabela 1.) & $\mathrm{CC}$ & $\mathrm{CM}$ & $\mathrm{CE}$ & $\mathrm{CO}$ & $\mathrm{BA}$ & $\mathrm{CA}$ & MI \\
\hline 97. S. guianensis (Aubl.) Benth. & & & $\mathrm{A}(\mathrm{R})$ & & & A (R) & $\mathrm{A}(\mathrm{O})$ \\
\hline 98. S. sinemariensis Aubl. & & & & & & & $\mathrm{A}(\mathrm{O})$ \\
\hline \multicolumn{8}{|l|}{ 22. Erythroxylaceae } \\
\hline 99. Erythroxylum engleri O. E. Schulz & & & $\operatorname{Ar}(\mathrm{R})$ & & & & \\
\hline 100. E. suberosum St. Hil. & $\operatorname{Ar}(\mathrm{O})$ & $\operatorname{Ar}(\mathrm{F})$ & $\operatorname{Ar}(\mathrm{O})$ & & & & \\
\hline 101. E. testaceum Peyr. & & & & & & & $\operatorname{Ar}(\mathrm{R})$ \\
\hline 102. E. tortuosum Mart. & & & $\mathrm{Sa}(\mathrm{R})$ & & & & \\
\hline \multicolumn{8}{|l|}{ 23. Euphorbiaceae } \\
\hline 103. Alchornea schomburgkii Klotzsch & & & $\mathrm{A}(\mathrm{R})$ & & & $\mathrm{A}(\mathrm{O})$ & \\
\hline 104. A. gardneri Muell.-Arg. & & & & & & & $\operatorname{Ar}(\mathrm{F})$ \\
\hline 105. Chaetocarpus echinocarpus (Baill.) Ducke & & & & & & & $\mathrm{A}(\mathrm{C})$ \\
\hline 106. Croton cuneatus Klotysch & & & & & & $\operatorname{Ar}(\mathrm{O})$ & $\operatorname{Ar}(\mathrm{O})$ \\
\hline 107. Mabea pohliana (Benth.) Muell.-Arg. & & $\operatorname{Ar}(\mathrm{R})$ & & & & $\mathrm{A}(\mathrm{C})$ & $\mathrm{A}(\mathrm{C})$ \\
\hline 108. Maprounea guianensis Aubl. & A (R) & $\mathrm{A}(\mathrm{R})$ & A (R) & $\mathrm{A}(\mathrm{C})$ & $\mathrm{A}(\mathrm{R})$ & & $A(R)$ \\
\hline 109. Pera coccinea (Benth.) Muell.-Arg. & & & & & & $\mathrm{A}(\mathrm{O})$ & \\
\hline 110. Sapium longifolium (Muell.-Arg.) Huber & & $\operatorname{Ar}(\mathrm{R})$ & & & & & \\
\hline 111. Sapium sp1 & & & & & & & $\mathrm{A}(\mathrm{O})$ \\
\hline 112. Sapium sp2 & & & & & & & $\operatorname{Ar}(\mathrm{O})$ \\
\hline \multicolumn{8}{|l|}{ 24. Fabaceae } \\
\hline 113. Acosmium dasycarpum (Vogel) Yakovlev & $\operatorname{Ar}(\mathrm{R})$ & $\mathrm{A}(\mathrm{O})$ & $\mathrm{A}(\mathrm{O})$ & & & & \\
\hline 114. A. nitens (Vogel) Yakovlev & & & & & & $\mathrm{A}(\mathrm{C})$ & $\mathrm{A}(\mathrm{A})$ \\
\hline 115. Andira cuyabensis Benth. & $\mathrm{A}(\mathrm{O})$ & $\mathrm{A}(\mathrm{F})$ & $\mathrm{A}(\mathrm{C})$ & $\mathrm{A}(\mathrm{O})$ & $A(R)$ & $A(R)$ & \\
\hline 116. Bowdichia virgilioides H.B.K. & & A (F) & $\mathrm{A}(\mathrm{O})$ & & & & \\
\hline 117. Dipteryx alata Vogel & $\mathrm{A}(\mathrm{O})$ & $\mathrm{A}(\mathrm{C})$ & $\mathrm{A}(\mathrm{O})$ & & & & \\
\hline 118. Luetzelburgia praecox (Harms) Harms & & A (R) & $\operatorname{Ar}(\mathrm{R})$ & & & & \\
\hline 119. Machaerium acutifolium Vogel & & & $A(R)$ & & & & \\
\hline 120. Platypodium elegans Vogel & & & & A (R) & & & \\
\hline 121. Pterodon pubescens Benth. & & & & $\mathrm{A}(\mathrm{O})$ & & & \\
\hline 122. Vatairea macrocarpa (Benth.) Ducke & $\mathrm{A}(\mathrm{O})$ & $\mathrm{A}(\mathrm{C})$ & $\mathrm{A}(\mathrm{F})$ & & $A(R)$ & & \\
\hline \multicolumn{8}{|l|}{ 25. Flacourtiaceae } \\
\hline 123. Casearia sylvestris $\mathrm{Sw}$. & & $\operatorname{Ar}(F)$ & $\mathrm{A}(\mathrm{O})$ & & & & \\
\hline 124. Homalium mattogrossense Malme & & & & & & & A (F) \\
\hline \multicolumn{8}{|l|}{ 26. Hippocrateaceae } \\
\hline 125. Anthodon decussatum Ruiz \& Pav. & & & & & & & $\mathrm{L}(\mathrm{O})$ \\
\hline 126. Cheiloclinium cognatum (Miers) A. C. Smith & & & & & & & $\operatorname{Ar}(O)$ \\
\hline 127. Peritassa campestris (Camb.) A. C. Smith & & $\operatorname{Ar}(\mathrm{R})$ & & & & & \\
\hline 128. P. laevigata (Hoffmanns. ex Link) A. C. Smith & & & & & $\mathrm{L}(\mathrm{O})$ & $\mathrm{L}(\mathrm{R})$ & $\mathrm{L}(\mathrm{O})$ \\
\hline 129. Salacia crassifolia (Mart.) G. Don & & $\operatorname{Ar}(\mathrm{R})$ & & & & & $\operatorname{Ar}(\mathrm{R})$ \\
\hline 130. S. elliptica (Mart.) G. Don & & & $\operatorname{Ar}(\mathrm{R})$ & $\mathrm{A}(\mathrm{O})$ & & & \\
\hline 131. Tontelea brachypoda Miers & & & $\mathrm{Sa}(\mathrm{O})$ & & & & \\
\hline \multicolumn{8}{|l|}{ 27. Icacinaceae } \\
\hline 132. Emmotum nitens (Benth.) Miers & $\operatorname{Ar}(\mathrm{R})$ & $\mathrm{A}(\mathrm{O})$ & $\mathrm{A}(\mathrm{F})$ & $\mathrm{A}(\mathrm{C})$ & A (F) & & \\
\hline \multicolumn{8}{|l|}{ 28. Lacistemataceae } \\
\hline \multirow{2}{*}{\multicolumn{8}{|c|}{$\begin{array}{l}\text { 29. Lauraceae } \\
\text { 2. Kas }\end{array}$}} \\
\hline & & & & & & & \\
\hline 134. Mezilaurus crassiramea (Meissn.) Taub. & & & A (R) & & & & \\
\hline 135. Nectandra $\mathrm{sp}$. & & & & $\mathrm{A}(\mathrm{O})$ & & & $A(R)$ \\
\hline 136. Ocotea guianensis Aubl. & & & & & & & $\mathrm{A}(\mathrm{C})$ \\
\hline 137. Lauraceae N.I. & $\operatorname{Ar}(\mathrm{R})$ & $\operatorname{Ar}(\mathrm{C})$ & & & & & $\mathrm{A}(\mathrm{C})$ \\
\hline \multicolumn{8}{|l|}{ 30. Loganiaceae } \\
\hline 138. Antonia ovata Pohl. (Vog.) & & & $\operatorname{Ar}(\mathrm{O})$ & $\operatorname{Ar}(\mathrm{R})$ & & & \\
\hline 139. Strychnos pseudo-quina A. St. Hil. & & A (R) & $\mathrm{A}(\mathrm{O})$ & & & & \\
\hline \multicolumn{8}{|l|}{ 31. Lythraceae } \\
\hline 140. Lafoensia pacari A. St. Hil. & $\mathrm{A}(\mathrm{O})$ & $\mathrm{A}(\mathrm{R})$ & $A(F)$ & & & & \\
\hline 141. Physocalymma scaberrimum Pohl & & & $\mathrm{A}(\mathrm{O})$ & $\mathrm{A}(\mathrm{C})$ & A (F) & & \\
\hline \multicolumn{8}{|l|}{ 32. Malpighiaceae } \\
\hline 142. Banisteriopsis pubipetala (A. Juss.) Cuatr. & & $\operatorname{Ar}(\mathrm{O})$ & $\operatorname{Ar}(\mathrm{O})$ & & & & \\
\hline 143. Byrsonima coccolobifolia H.B.K. & & A (F) & $\mathrm{A}(\mathrm{F})$ & & & & \\
\hline 144. B. crassa Nied. & & & $\operatorname{Ar}(O)$ & & & & \\
\hline 145. B. intermedia A. Juss. & & $\mathrm{A}(\mathrm{O})$ & $\mathrm{A}(\mathrm{R})$ & A (F) & $\mathrm{A}(\mathrm{O})$ & & A (R) \\
\hline 146. B. orbignyana A. Juss. & A (R) & $\operatorname{Ar}(\mathrm{F})$ & $\operatorname{Ar}(R)$ & & & $\operatorname{Ar}(\mathrm{F})$ & $\operatorname{Ar}(\mathrm{R})$ \\
\hline 147. B. verbascifolia (L.) Rich. ex A. Juss. & & & $\mathrm{A}(\mathrm{O})$ & & & & \\
\hline 148. Byrsonima sp. & & & & & & & A (F) \\
\hline
\end{tabular}




\begin{tabular}{|c|c|c|c|c|c|c|c|}
\hline Famílias/Espécies (continuação tabela 1.) & $\mathrm{CC}$ & $\mathrm{CM}$ & $\mathrm{CE}$ & $\mathrm{CO}$ & BA & $\mathrm{CA}$ & MI \\
\hline \multicolumn{7}{|l|}{ 33. Melastomataceae } & \\
\hline 150. Miconia albicans (Sw.) Triana & & & $\mathrm{Sa}(\mathrm{R})$ & $\operatorname{Ar}(\mathrm{R})$ & & $\operatorname{Ar}(\mathrm{R})$ & \\
\hline 151. M. pyrifolia Naud sensu Cogn. & & & & & & & A (R) \\
\hline \multicolumn{7}{|l|}{ 34. Meliaceae } & $\operatorname{Ar}(\mathrm{R})$ \\
\hline $\begin{array}{l}\text { 153. Cedrela fissilis Vell. } \\
\text { 35. Memecylaceae }\end{array}$ & & $\mathrm{A}(\mathrm{O})$ \\
\hline 154. Mouriri apiranga Spruce ex Triana & & & & & & $\mathrm{A}(\mathrm{O})$ & $\mathrm{A}(\mathrm{C})$ \\
\hline 155. M. elliptica Mart. & & A (R) & $\mathrm{A}(\mathrm{O})$ & $\operatorname{Ar}(\mathrm{O})$ & $\operatorname{Ar}(\mathrm{R})$ & & \\
\hline $\begin{array}{l}\text { 156. M. pusa Gardner } \\
\text { 36. Menispermaceae }\end{array}$ & & & $\mathrm{A}(\mathrm{C})$ & & & & $\mathrm{A}(\mathrm{O})$ \\
\hline 157. Abuta grandifolia (Mart.) Sandw. & & & & $\operatorname{Ar}(\mathrm{O})$ & & & \\
\hline 158. A. selloana (Benth.) Eichler & & $\operatorname{Ar}(\mathrm{R})$ & & & & & \\
\hline \multicolumn{8}{|l|}{ 37. Mimosaceae } \\
\hline 159. Albizia polyantha (Spreng. f.) Lewis & & & & & & & $A(R)$ \\
\hline 160. Enterolobium schomburgkii (Benth.) Benth. & & & & & & & $A(R)$ \\
\hline 161. Inga sp. & & & & & & & A (F) \\
\hline 162. Mimosa sp. & & & & & & & $\operatorname{Ar}(\mathrm{O})$ \\
\hline 163. Pithecellobium sp1 & & & & & A (R) & & $\mathrm{A}(\mathrm{C})$ \\
\hline 164. Pithecellobium sp2 & & & & & & & $\mathrm{A}(\mathrm{O})$ \\
\hline 165. Plathymenia reticulata Benth. & A (R) & A (R) & $\operatorname{Ar}(\mathrm{O})$ & & & & \\
\hline 166. Stryphnodendron coriaceum Benth. & & & & $\mathrm{A}(\mathrm{O})$ & & & $\mathrm{A}(\mathrm{O})$ \\
\hline 167. S. obovatum Benth. & & & $\operatorname{Ar}(\mathrm{O})$ & & & & \\
\hline \multicolumn{8}{|l|}{ 38. Monimiaceae } \\
\hline 168. Siparuna guianensis Aubl. & & & & $\operatorname{Ar}(\mathrm{O})$ & & & $\operatorname{Ar}(\mathrm{O})$ \\
\hline \multicolumn{8}{|l|}{ 39. Moraceae } \\
\hline 169. Brosimum cf. lactescens (S. Moore) C.C. Berg. & & & & & & & $\mathrm{A}(\mathrm{O})$ \\
\hline 170. B. gaudichaudii Tréc. & & $\mathrm{Sa}(\mathrm{O})$ & $\operatorname{Ar}(\mathrm{O})$ & & & & \\
\hline 171. Ficus sp. & & & & & & A (R) & A (R) \\
\hline 172. Pseudolmedia laevigata Tréc. & & & & A (F) & $\mathrm{A}(\mathrm{O})$ & $\mathrm{A}(\mathrm{O})$ & A (F) \\
\hline 173. Sorocea guilleminiana Gaud. & & & & & A (F) & & \\
\hline 174. Sorocea sprucei (Baill.) Macbr. & & & $\mathrm{Sa}(\mathrm{R})$ & $\mathrm{Sa}(\mathrm{O})$ & & & $\mathrm{Sa}(\mathrm{R})$ \\
\hline \multicolumn{8}{|l|}{ 40. Myristicaceae } \\
\hline 175. Virola sebifera Aubl. & & & $\mathrm{A}(\mathrm{R})$ & $\mathrm{A}(\mathrm{O})$ & & & \\
\hline $\begin{array}{l}\text { 176. V. urbaniana Warb. } \\
\text { 41. Mvrsinaceae }\end{array}$ & & & & & & & $A(R)$ \\
\hline \multicolumn{8}{|l|}{ 41. Myrsinaceae } \\
\hline 177. Cybianthus detergens Mart. & & $\operatorname{Ar}(\mathrm{R})$ & & $\operatorname{Ar}(\mathrm{O})$ & & $\operatorname{Ar}(\mathrm{O})$ & \\
\hline \multicolumn{8}{|l|}{ 42. Myrtaceae } \\
\hline 178. Campomanesia sp & & $\mathrm{A}(\mathrm{O})$ & $\mathrm{A}(\mathrm{O})$ & & $\mathrm{A}(\mathrm{O})$ & & \\
\hline 179. Eugenia aurata O. Berg & & $\operatorname{Ar}(\mathrm{F})$ & & & & & \\
\hline 180. E. chrysantha O. Berg & & $\operatorname{Ar}(\mathrm{F})$ & $\operatorname{Ar}(\mathrm{O})$ & & & & \\
\hline 181. E. inundata $\mathrm{DC}$. & & & & $\mathrm{A}(\mathrm{O})$ & & & A (R) \\
\hline 182. E. cf. klotzschiana O. Berg & $\operatorname{Ar}(\mathrm{R})$ & $\operatorname{Ar}(\mathrm{O})$ & $\mathrm{A}(\mathrm{R})$ & & & & \\
\hline 183. E. cf. pyriformis Camb. & & & & & & & $\operatorname{Ar}(\mathrm{O})$ \\
\hline 184. Eugenia $\mathrm{sp} 1$ & & $\operatorname{Ar}(\mathrm{O})$ & $\operatorname{Ar}(\mathrm{O})$ & & & & \\
\hline 185. Eugenia $\mathrm{sp} 2$ & & $\mathrm{~A}(\mathrm{O})$ & $\mathrm{A}(\mathrm{O})$ & $\mathrm{A}(\mathrm{O})$ & $\mathrm{A}(\mathrm{O})$ & & \\
\hline 186. Myrcia tomentosa (Aubl.) DC. & & $\mathrm{A}(\mathrm{O})$ & $\mathrm{A}(\mathrm{O})$ & & & & \\
\hline 187. Psidium aff. kennedyanum Morong. & & & & & & & $\operatorname{Ar}(\mathrm{O})$ \\
\hline 188. Psidium sp. & & & & & & & $\operatorname{Ar}(\mathrm{F})$ \\
\hline \multicolumn{8}{|l|}{ 43. Nyctaginaceae } \\
\hline 189. Neea hermaphrodita S. Moore & & & & & & & $\operatorname{Ar}(\mathrm{R})$ \\
\hline 190. N. macrophylla Poepp. \& Engl. & & & & & & & $\operatorname{Ar}(\mathrm{O})$ \\
\hline 191. N. theifera Oerst. & & $\operatorname{Ar}(\mathrm{O})$ & $\mathrm{Sa}(\mathrm{R})$ & & & & \\
\hline \multicolumn{8}{|l|}{ 44. Ochnaceae } \\
\hline 192. Ouratea castaneaefolia (DC.) Engl. & & $\operatorname{Ar}(\mathrm{O})$ & $\operatorname{Ar}(\mathrm{R})$ & A (F) & $\operatorname{Ar}(\mathrm{R})$ & & $\mathrm{A}(\mathrm{O})$ \\
\hline 193. O. hexasperma (St. Hil.) Baill. & & $\mathrm{A}(\mathrm{R})$ & $\mathrm{A}(\mathrm{O})$ & $A(R)$ & & & \\
\hline 194. O. nana (St. Hil.) Engl. & & & $\mathrm{Sa}(\mathrm{O})$ & & & & \\
\hline \multicolumn{8}{|l|}{ 45. Olacaceae } \\
\hline 195. Cathedra acuminata (Benth.) Miers & & & & & & A (R) & $\mathrm{A}(\mathrm{F})$ \\
\hline 196. Heisteria ovata Benth. & & & & $\operatorname{Ar}(F)$ & & & \\
\hline 197. Minquartia guianensis Aubl. & & & & & & & $\mathrm{A}(\mathrm{O})$ \\
\hline
\end{tabular}




\begin{tabular}{|c|c|c|c|c|c|c|c|}
\hline Famílias/Espécies (continuação tabela 1.) & $\mathrm{CC}$ & $\mathrm{CM}$ & $\mathrm{CE}$ & $\mathrm{CO}$ & BA & $\mathrm{CA}$ & MI \\
\hline \multicolumn{8}{|l|}{ 46. Opiliaceae } \\
\hline 198. Agonandra brasiliensis Miers & & & A (F) & & & & $A(R)$ \\
\hline \multicolumn{8}{|l|}{ 47. Polygalaceae } \\
\hline 199. Bredemeyera floribunda Willd. & & $\operatorname{Ar}(\mathrm{R})$ & $\mathrm{Sa}(\mathrm{R})$ & & & & \\
\hline \multicolumn{8}{|l|}{ 48. Polygonaceae } \\
\hline $\begin{array}{l}\text { 200. Coccoloba molis Casar } \\
\text { 201. C. ochreolata Wedd. }\end{array}$ & & & A (R) & & $\operatorname{Ar}(\mathrm{F})$ & & $A(R)$ \\
\hline 202. Coccoloba sp. & & & & & & & $\operatorname{Ar}(\mathrm{R})$ \\
\hline \multicolumn{8}{|l|}{ 49. Proteaceae } \\
\hline 203. Euplassa inaequalis (Pohl) Engl. & $\mathrm{A}(\mathrm{R})$ & $\mathrm{A}(\mathrm{O})$ & $\mathrm{A}(\mathrm{O})$ & $\mathrm{A}(\mathrm{F})$ & $\mathrm{A}(\mathrm{O})$ & & \\
\hline 204. Panopsis rubescens (Pohl) Pittier & & & & & & $\mathrm{A}(\mathrm{C})$ & A (A) \\
\hline 205. Roupala montana Aubl. & & & $\mathrm{A}(\mathrm{O})$ & $\mathrm{A}(\mathrm{C})$ & & & \\
\hline 206. $R$. nitida Rudge & & & & & & A (R) & $A(R)$ \\
\hline \multicolumn{8}{|l|}{ 50. Quiinaceae } \\
\hline 207. Quiina cf. paraensis Pires \& Froes & & & & & & & $\mathrm{A}(\mathrm{C})$ \\
\hline \multicolumn{8}{|l|}{ 51. Rhamnaceae } \\
\hline 208. Rhamnidium elaeocarpum Reissek & & & & $\mathrm{A}(\mathrm{O})$ & & $\mathrm{A}(\mathrm{O})$ & \\
\hline \multicolumn{8}{|l|}{ 52. Rubiaceae } \\
\hline 209. Alibertia edulis (L.C. Rich.) A.C. Rich. & $\operatorname{Ar}(\mathrm{R})$ & $\operatorname{Ar}(\mathrm{F})$ & $\mathrm{A}(\mathrm{O})$ & & $\operatorname{Ar}(\mathrm{O})$ & $\operatorname{Ar}(\mathrm{R})$ & $\operatorname{Ar}(\mathrm{R})$ \\
\hline 210. A. sessilis (Vell.) K. Schum. & $\operatorname{Ar}(\mathrm{R})$ & $\operatorname{Ar}(\mathrm{R})$ & $\operatorname{Ar}(\mathrm{O})$ & $\operatorname{Ar}(\mathrm{O})$ & & & \\
\hline 211. Amaioua guianensis Aubl. & & & & & $\mathrm{A}(\mathrm{O})$ & $\mathrm{A}(\mathrm{O})$ & $\mathrm{A}(\mathrm{C})$ \\
\hline 212. Chomelia ribesioides Benth. ex A. Gray & & & & & & & $\operatorname{Ar}(\mathrm{F})$ \\
\hline 213. Coussarea platyphylla Muell.-Arg. & & & & & $\operatorname{Ar}(\mathrm{O})$ & & \\
\hline 214. Genipa americana L. & & & & & & & A (F) \\
\hline 215. Psychotria prunifolia (H.B.K.) Steyern. & & & & & & & $\mathrm{Sa}(\mathrm{R})$ \\
\hline 216. Rudgea amazonica Muell.-Arg. & & & $\mathrm{Sa}(\mathrm{R})$ & & & & \\
\hline 217. Tocoyena formosa (Cham. \& Schltdl.) K. Schum. & $\mathrm{Sa}(\mathrm{O})$ & $\mathrm{Sa}(\mathrm{F})$ & $\operatorname{Ar}(\mathrm{O})$ & & & & \\
\hline 218. Uncaria guianensis (Aubl.) J. F. Gmel. & & & & & & & $\mathrm{L}(\mathrm{F})$ \\
\hline \multicolumn{8}{|l|}{ 53. Rutaceae } \\
\hline 219. Zanthoxylum riedelianum Engl. & & $\mathrm{A}(\mathrm{R})$ & & & & & \\
\hline \multicolumn{8}{|l|}{ 54. Sapindaceae } \\
\hline 220. Magonia pubescens St. Hil. & & $\mathrm{A}(\mathrm{O})$ & $\mathrm{A}(\mathrm{O})$ & A (F) & & & \\
\hline 221. Matayba guianensis Aubl. & & $\mathrm{A}(\mathrm{O})$ & $\mathrm{A}(\mathrm{O})$ & $\mathrm{A}(\mathrm{O})$ & & & \\
\hline 222. Matayba sp. & & & & $\mathrm{A}(\mathrm{O})$ & $\operatorname{Ar}(\mathrm{O})$ & & \\
\hline 223. Serjania glutinosa Radlk. & & $\mathrm{L}(\mathrm{R})$ & $\mathrm{L}(\mathrm{O})$ & $\mathrm{L}(\mathrm{R})$ & & $\mathrm{L}(\mathrm{R})$ & $\mathrm{L}(\mathrm{F})$ \\
\hline \multicolumn{8}{|l|}{ 55. Sapotaceae } \\
\hline 224. Chrysophyllum sp. & & & & & & & $\mathrm{A}(\mathrm{O})$ \\
\hline 225. Micropholis venulosa (Mart. \& Eichl.) Pierre & & & & & & $\mathrm{A}(\mathrm{O})$ & $\mathrm{A}(\mathrm{F})$ \\
\hline 226. Pouteria cf. glomerata (Miq.) Radlk. & & & & & & & $A(R)$ \\
\hline 227. P. macrophylla (Lam.) Eyma & & & & & & & $\mathrm{A}(\mathrm{C})$ \\
\hline 228. P. ramiflora (Mart.) Radlk. & $\mathrm{A}(\mathrm{O})$ & $\mathrm{A}(\mathrm{C})$ & $\mathrm{A}(\mathrm{C})$ & & & & \\
\hline 229. P. torta (Mart.) Radlk. & & & $\mathrm{A}(\mathrm{R})$ & & & & $A(R)$ \\
\hline 230. Pouteria sp. & & & & & & & $A(R)$ \\
\hline 231. Sideroxylon venulosum Mart. \& Eichl. & & & & & & & A (F) \\
\hline \multicolumn{8}{|l|}{ 56. Simaroubaceae } \\
\hline 232. Simaba intermedia Mansf. & & & & & & & $\operatorname{Ar}(\mathrm{O})$ \\
\hline 233. Simarouba versicolor St. Hil. & & $\mathrm{A}(\mathrm{O})$ & A (F) & & & A (R) & \\
\hline \multicolumn{8}{|l|}{ 57. Sterculiaceae } \\
\hline 234. Helicteres brevispira A. Juss. & & & $\mathrm{Sa}(\mathrm{R})$ & & & & \\
\hline \multicolumn{8}{|l|}{ 58. Ternstroemiaceae } \\
\hline 235. Ternstroemia candolleana Wawra & & & & & & $\mathrm{A}(\mathrm{C})$ & A (F) \\
\hline \multicolumn{8}{|l|}{ 59. Tiliaceae } \\
\hline 236. Luehea candicans Mart. & & & & & $\mathrm{A}(\mathrm{R})$ & & \\
\hline 60. Verbenaceae & & & & & & & \\
\hline 237. Aegiphila cf. Ihotzkiana L. & & $\mathrm{A}(\mathrm{O})$ & & & & & \\
\hline 238. Vitex polygama Cham. & & & & $\mathrm{A}(\mathrm{R})$ & $\mathrm{A}(\mathrm{O})$ & & $\mathrm{A}(\mathrm{R})$ \\
\hline 61. Vitaceae & & & & & & & \\
\hline 239. Cissus erosa L.C. Rich. & & & & $\mathrm{L}(\mathrm{O})$ & & & $\mathrm{L}(\mathrm{O})$ \\
\hline 240. C. spinosa Camb. & & $\mathrm{L}(\mathrm{R})$ & & & & & $\mathrm{L}(\mathrm{O})$ \\
\hline 62. Vochysiaceae & & & & & & & \\
\hline 241. Callisthene fasciculata (Spreng.) Mart. & & $\mathrm{A}(\mathrm{O})$ & $\mathrm{A}(\mathrm{O})$ & $\mathrm{A}(\mathrm{O})$ & A (R) & & A (R) \\
\hline 242. Qualea grandiflora Mart. & & $\mathrm{A}(\mathrm{O})$ & $\mathrm{A}(\mathrm{O})$ & $\mathrm{A}(\mathrm{O})$ & & & \\
\hline 243. Q. multiflora Mart. & & & $\mathrm{A}(\mathrm{R})$ & A (F) & $A(R)$ & & \\
\hline
\end{tabular}




\begin{tabular}{|c|c|c|c|c|c|c|c|}
\hline Famílias/Espécies (continuação tabela 1.) & $\mathrm{CC}$ & $\mathrm{CM}$ & $\mathrm{CE}$ & $\mathrm{CO}$ & BA & $\mathrm{CA}$ & MI \\
\hline 244. Q. parviflora Mart. & $\mathrm{A}(\mathrm{F})$ & $\mathrm{A}(\mathrm{F})$ & $\mathrm{A}(\mathrm{C})$ & $\mathrm{A}(\mathrm{F})$ & & & \\
\hline 245. Salvertia convallariodora St. Hil. & $\mathrm{A}(\mathrm{R})$ & & A (F) & & & & \\
\hline 246. Vochysia divergens Pohl & & & & & $\mathrm{A}(\mathrm{O})$ & $\mathrm{A}(\mathrm{O})$ & $\mathrm{A}(\mathrm{C})$ \\
\hline 247. V. haenkeana Mart. & & & & $\mathrm{A}(\mathrm{O})$ & & & $\mathrm{A}(\mathrm{O})$ \\
\hline 248. V. rufa Mart. & $\operatorname{Ar}(\mathrm{A})$ & $\operatorname{Ar}(\mathrm{C})$ & $\operatorname{Ar}(\mathrm{O})$ & & & & \\
\hline
\end{tabular}

Inundáveis por extensas e estreitas faixas de Campo Limpo, com vegetação predominante de gramíneas e eventuais sub-arbustos, compondo, assim, um "cerrado de alto interflúvio", de acordo com Oliveira-Filho (1989).

Com relação ao estado geral de conservação, verificou-se a presença de troncos queimados e também intenso rebrotamento dos mesmos, sugerindo uma satisfatória reconstituição da comunidade após a passagem do fogo. As condições gerais desta fitofisionomia podem ser consideradas boas, apesar da influência do pastoreio e do fogo.

Mata Inundável - de acordo com Ratter et al. (1978b) e Ratter (1987), as matas inundáveis são formações florestais, estruturalmente simples, que ocorrem em áreas planas circundando lagos ou margeando rios, permanecendo inundadas durante longos períodos na época das chuvas. No presente estudo, foram observadas matas inundáveis nas margens do Rio das Mortes, Rio Araguaia, Rio Cristalino e lagos, incluindo algumas matas de galeria inundáveis.

O termo "Mata de Galeria Alagada" foi adotado por Ratter et al. (1973), segundo os quais a vegetação está associada a um curso d'água e o solo permanece encharcado a maior parte do ano. Ribeiro \& Walter (1998) sugerem a utilização do termo "inundável" ao invés de "alagada", pois este último não fornece a idéia de que variações estacionais possam ocorrer. Este tipo de mata estaria ainda subordinado ao tipo "Mata de Galeria" proposto por Ribeiro et al. (1983). Eiten (1975) sugere a ocorrência de dois tipos de mata de galeria na região da Serra do Roncador-MT, uma inundável e outra não-inundável, com variação florística e estrutural bem definida e variação abrupta para os campos de solos hidromórficos.

As Matas Inundáveis do presente estudo localizam-se em regiões de planície, relevo plano, solo mal drenado e coberto com espessa $(>20 \mathrm{~cm})$ camada de húmus e liter. $\mathrm{O}$ solo apresentou textura argilosa, coloração preta e ausência de rochosidade. As árvores apresentaram marcas que indicaram a altura atingida pelo nível d'água na última enchente $(>2 \mathrm{~m})$, aspecto verificado também por Ratter (1987).

Algumas espécies localizadas nas margens dos braços do Rio (localmente denominados de Boca Franca, quando ainda mantém ligação com o rio e, Lago, quando totalmente isolados) apresentaram raízes escoras e raízes aéreas que se lançam perpendicularmente em direção à superfície da água. Ratter (1987) menciona a ocorrência de raízes aéreas nas Matas Inundáveis do Parque Nacional do Araguaia, sugerindo inclusive uma "aparência de floresta encantada".

Foram observados dois estratos nas Matas Inundáveis, o arbóreo (aberto) com espécies atingindo até $25 \mathrm{~m}$ de altura e o arbustivo (denso), com espécies entre 2 e $5 \mathrm{~m}$ de altura. $\mathrm{O}$ estrato arbóreo foi caracterizado principalmente por Calophyllum brasiliense, Diospyros obovata, Vochysia divergens, Amaioua guianensis, Panopsis rubescens, Chaetocarpus echinocarpus, Licania apetala e Acosmium nitens. $\mathrm{O}$ estrato arbustivo foi representado por Astrocaryum vulgare, Psidium sp. e Chomelia ribesioides. Estas matas assemelharam-se floristicamente com 
as matas estudadas por Ratter et al. (1978b) e Ratter (1987).

Nascimento \& Cunha (1989) verificaram que Vochysia divergens é uma espécie colonizadora de campos naturais inundáveis no pantanal de Poconé-MT, onde é conhecida como Cambará. Estas concentrações de $V$. divergens, denominadas em Poconé como Cambarazais, possuem formação e ocupação, provavelmente, a partir de sementes vindas de indivíduos localizados em matas ciliares próximas. No presente estudo foram identificadas diversas manchas de $V$. divergens (localmente denominada por Cangerana), em padrão semelhante àquele verificado no pantanal de Poconé-MT.

As características de conservação, da fitofisionomia em questão, foram satisfatórias, entretanto, ocorreram evidências de perturbação antrópica através da retirada seletiva de Calophyllum brasiliense e do pastoreio extensivo que ocasiona trechos de erosão às margens dos "lagos", nos pontos de acesso do gado à água (bebedouros naturais).

Campo de Murunduns - de acordo com Araújo Neto et al. (1986), o termo "Campo de Murundu" tem no Brasil Central o sentido de um campo úmido com "ilhas" de terra elevada, revestidas com espécies de cerrado, denominadas de "murunduns" e ocorrendo em um padrão regular. Oliveira-Filho \& Furley (1990) sugerem ainda que na região do Vale do Araguaia MT/GO a designação regional destas ilhas é "monchão".

Silva Jr. \& Felfili (1996) acrescentam que nestas ilhas ou murunduns as condições de drenagem condicionam a boa aeração do solo favorecendo a propagação de espécies arbóreas oriundas dos cerrados nas vizinhanças, sendo que, os térmitas (cupins) podem desempenhar um papel importante na formação destes campos. Ratter (1987) verificou que as árvores e arbustos localizados sobre os murunduns são representantes de espéci- es do cerrado, apesar de ocorrerem também espécies de mata.

$\mathrm{Na}$ área estudada, os Campos de Murunduns localizam-se em regiões de extensa planície de inundação caracterizada por um relevo plano. A textura dos solos variou de areno-argilosa a argilosa. No período das chuvas, as áreas de vegetação graminosa e herbácea (de acordo com Ribeiro \& Walter (1998), denominada de Campo Limpo) são cobertas por uma lâmina d'água de altura variável e os murunduns, cobertos por vegetação arbustivo-arbórea de cerrado, não são atingidos pela água. Verificou-se também que praticamente todos os murunduns apresentaram um cupinzeiro associado (em geral localizado no centro).

A vegetação desta fitofisionomia deve ser diferenciada entre aquela localizada sobre os murunduns e aquela das áreas de campo limpo. Sobre os murunduns identificaram-se três estratos de vegetação. O primeiro foi composto por árvores que variaram de 5 a $10 \mathrm{~m}$ de altura (raramente atingindo $15 \mathrm{~m}$ ), sendo caracterizado por Dipteryx alata, Vatairea macrocarpa, Andira cuyabensis, Pouteria ramiflora, Tabebuia aurea e Curatella americana. $\mathrm{O}$ segundo foi caracterizado por arbustos e sub-arbustos (entre 1 e $5 \mathrm{~m}$ de altura) representados por Erythroxylum suberosum, Vochysia rufa, Copaifera martii, Bauhinia rufa e Byrsonima orbignyana e o terceiro (herbáceo) foi composto principalmente por espécies do gênero Hyptis, plântulas de espécies lenhosas e representantes da família Poaceae. Dentre as árvores típicas de murunduns, Ratter (1987) também citou como frequientes Tabebuia caraiba $(=T$. aurea), Curatella americana e Vatairea macrocarpa.

O Campo Limpo (que circunda os murunduns) foi caracterizado por diversas espécies da família Poaceae, algumas Cyperaceae, Iridaceae, Labiateae e Eriocaulaceae, sendo que, eventualmente ve- 
rificou-se a ocorrência de plântulas e sub-arbustos das espécies lenhosas dos murunduns. Em algumas manchas ocorreu a presença dominante de Anacardium humile.

Os Campos de Murunduns apresentaram padrões distintos em função do tipo e grau de encharcamento do solo. Aparentemente, nas áreas onde o nível d'água permanece elevado na época das chuvas ou o período de encharcamento é maior, Curatella americana encontra-se bastante comum nas bordas dos murunduns. Oliveira-Filho \& Furley (1990) citaram esta espécie como uma das mais resistentes aos excessos de água no solo. Outra característica importante foi que neste caso os murunduns tenderam a ser maiores (área ocupada e altura), quando comparados aos murunduns de solos melhor drenados.

O estado de conservação desta fitofisionomia é bom, entretanto, a presença de troncos queimados e vestígios (fezes) que indicam a presença de bovinos demonstram certo grau de perturbação.

Cerradão - de acordo com Veloso et al. (1991) o Cerradão ou Savana Florestada é um sub-grupo de formação com fisionomia típica e característica, ocorrendo em áreas areníticas lixiviadas de solos profundos. Ribeiro \& Walter (1998) caracterizam o cerradão, do ponto de vista fisionômico, como uma floresta, mas sendo floristicamente mais similar ao cerrado.

Ratter et al. (1973) citaram três tipos de cerradão na região nordeste mato-grossense, sendo eles, Cerradão de Hirtella glandulosa, Cerradão de Magonia pubescens Callisthene fasciculata e Cerradão Indiferenciado. Comparando-se as características estruturais destes com o cerradão analisado neste trabalho, não foi possível identificar estreita relação entre os mesmos, principalmente se considerarmos que, em geral, o cerradão em questão localiza-se em áreas de contato com Mata Inundável, por um lado, e Cerrado s.s por outro. Ratter (1987) estudou um Complexo Cerrado/Cerradão Distrófico e IBDF (1981) caracterizou um Cerradão no Parque Nacional do Araguaia cujas espécies coincidem com as mais freqüentes identificadas no cerradão do presente estudo.

O Cerradão da área estudada foi caracterizado por um estrato arbóreo, que variou de 10 a $17 \mathrm{~m}$ de altura, com Sclerolobium paniculatum, Hirtella glandulosa, Caryocar sp., Emmotum nitens, Roupala montana, Physocalymma scaberrimum e Protium heptaphyllum. O sub-bosque foi caracterizado por Heisteria ovata, Copaifera martii e Protium unifoliolatum.

O solo sob esta fitofisionomia apresentou textura arenosa a areno-argilosa, sendo aparentemente profundo e bem drenado. O estado de conservação é muito bom, não tendo sido verificadas evidências de perturbação recente.

Campo Cerrado de Vochysia rufa - estas áreas podem ser associadas à Savana Parque, proposta por Veloso et al. (1991) ou ao Campo Sujo, sugerido por Ribeiro \& Walter (1998), cuja fisionomia é composta essencialmente por um estrato graminoso e espécies arbóreas e arbustivas dispersas isoladamente. No presente estudo o Campo Cerrado de Vochysia rufa foi caracterizado como uma fitofisionomia independente em função da freqüente ocorrência na área e por apresentar características individuais que não permitiram incluí-lo em outra.

Neste caso, as árvores foram representadas principalmente por Vochysia rufa, atingindo em alguns locais uma acentuada monodominância. A fitofisionomia foi composta por um estrato arbóreo-arbustivo (entre 3 e $7 \mathrm{~m}$ de altura) e um estrato graminoso com representantes das famílias Poaceae, Xyridaceae, Iridaceae, Eriocaulaceae, Lythraceae, Labiateae e outras. Ratter (1987) e IBDF (1981) citaram V. rufa ocorrendo em áreas de Campo de Murunduns e Campo Inundado, respectivamente. 
O solo assemelhou-se estruturalmente àquele encontrado nos campos limpos das áreas de Campo de Murunduns, apresentando-se mal drenado no período das chuvas.

Com relação à espécie dominante ( $V$. rufa) verificou-se um padrão curioso com relação à posição de seu fuste, o qual encontrava-se geralmente inclinado na direção norte. Praticamente todos os indivíduos apresentaram esta inclinação, sendo que estudos posteriores são indispensáveis para elucidar os mecanismos envolvidos neste padrão.

Campo de Byrsonima orbignyana - o padrão de dominância de Byrsonima orbignyana nestes campos foi bem mais acentuado do que a dominância de $V$. rufa, no Campo Cerrado de $V$. rufa. Neste caso, são áreas que sofrem intenso encharcamento na época chuvosa (até 1,5m de água acima da superfície do solo), o solo é glei húmico e a declividade inferior às áreas adjacentes.

Esta fitofisionomia pode ser associada aos típicos "Canjiqueirais" do pantanal do Rio Paraguai, Poconé-MT (Pott \& Pott 1994) dominantes nos Campos Alagáveis. Ratter (1987) também cita a ocorrência de Byrsonima (Murici de Vargem) em áreas alagadas.

No presente estudo, B. orbignyana foi praticamente monodominante na fitofisionomia, sendo assim, eventuais espécies associadas não foram listadas.

Babaçual - Veloso et al. (1991) denominaram esta comunidade como Floresta Ombrófila Aberta Submontana com Palmeiras. Eiten (1994) e Lorenzi et al. (1996) a denominaram Babaçual, ou seja, trecho de Babaçú (Attalea speciosa) puro ou com pequena proporção de árvores de outro tipos. Ribeiro \& Walter (1998) denominaram esta fitofisionomia de Palmeiral, sugerindo que a presença de babaçú estaria associada a áreas antropizadas.

O babaçú encontrou-se abundante nestas áreas, apresentando indivíduos com até $18 \mathrm{~m}$ de altura. As demais espécies que com- puseram o estrato superior desta fitofisionomia foram representadas por Emmotum nitens, Sorocea guilleminiana, Physocalymma scaberrimum e Licania gardneri. $\mathrm{O}$ estrato arbustivo foi caracterizado por Lacistema aggregatum e Coccoloba ochreolata e o estrato herbáceo foi praticamente ausente. Ratter (1987) citou a ocorrência de babaçú em áreas de Cerradão Distrófico do Parque Nacional do Araguaia. Nos Campos de Murunduns, localizados em áreas adjacentes aos Babaçuais, a vegetação lenhosa sobre os murunduns foi caracterizada pela presença freqüiente de babaçús.

O solo apresentou textura argilo-arenosa, coloração cinza e encontrou-se coberto por uma espessa camada de folhas secas.

Caapões - esta fitofisionomia é denominada localmente como "Impuca". Caracterizou-se por apresentar solos de drenagem deficiente, coloração preta e textura argilosa. No período das chuvas (de acordo com moradores locais, principalmente entre janeiro e abril) estas áreas permanecem inundadas, formando bacias circundadas por campos limpos.

Nos Caapões a diversidade de espécies foi baixa, ocorrendo em muitos pontos a dominância de uma única espécie (Licania cf. parvifolia). Dentre as espécies mais comuns encontraram-se Acosmium nitens, Mabea pohliana, Panopsis rubescens e Sclerolobium froesii. Ratter et al. (1978b) e Ratter (1987) citaram estas duas últimas espécies como freqüentes em Matas Inundáveis.

$\mathrm{Na}$ área estudada, observou-se em um caapão a ocorrência de uma intensa queimada prescrita (provavelmente na última seca) que comprometeu drasticamente sua composição florística. Outra ameaça consiste na freqüente retirada de madeira, principalmente Sclerolobium froesii.

As informações relacionadas à distribuição das espécies registradas na área de estudo indicaram uma relevante diversidade de fitofisionomias, representadas principalmen- 
te por Campo de Murunduns, Mata Inundável e Cerrado s.s.

Padronizar a nomenclatura dos tipos fitofisionômicos do Cerrado não é uma tarefa fácil (Ribeiro \& Walter 1998), sendo assim, no presente estudo, foram adotados critérios baseados principalmente no amplo uso dos termos e na terminologia regional. Dentre os novos termos propostos, Campo Cerrado de Vochysia rufa e Campo de Byrsonima orbignyana apresentaram características típicas de savana parque e campo (Ribeiro \& Walter 1998), respectivamente, porém, com absoluta predominância das espécies que não poderiam deixar de ser mencionadas na terminologia sugerida.

Pode-se concluir que as fitofisionomias do Pantanal Mortes-Araguaia assemelham-se em alguns aspectos com aquelas do Pantanal do Rio Paraguai (ex: frequiência de cambarazais e canjiqueirais), entretanto, em outros apresentam particularidades (ex: no Pantanal Paraguai as comunidades de macrófitas aquáticas e os Caapões são muito mais freqüentes e abundantes; no Pantanal Mortes-Araguaia os Campos de Murunduns são mais freqüentes e abundantes e o Campo Cerrado de Vochysia rufa, aparentemente, é exclusivo deste último). Assim, considerandose as particularidades fisionômicas da região e a pressão imposta pela pecuária extensiva e pelo crescente fluxo de turistas, é imprescindível que se desencadeie um firme propósito de conservação, não somente visando a manutenção das características naturais da área, mas também para que sejam garantidos estudos mais intensivos para sua caracterização fisionômica e fisiográfica e posterior definição e planejamento de sistemas de unidade(s) de conservação que possam abranger a máxima diversidade florística e estrutural da região.

\section{Agradecimentos}

Somos gratos ao Dr. James Alexander Ratter pelo auxílio na identificação taxonômica e à UNEMAT -Campus Universitário de Nova Xavantina, pelo apoio durante os trabalhos de campo. Agradecemos também aos revisores anônimos, pelas valiosas sugestões.

\section{Referências bibliográficas}

Araújo Neto, M. D.; Furley, P. A.; Haridasan, M. \& Johnson, C. E. 1986. The murundus of the Cerrado region of Central Brazil. Journal of Tropical Ecology 2: 17-35.

Camargo, A. P. 1963. Clima do Cerrado. Pp. 75-95. In: M.G.Ferri (coord.). Simpósio sobre o cerrado. EdUSP, São Paulo-SP.

Castro, E. C. 1997. Estrutura de paisagem da vazante do Rio Araguaia. p. 278-285. In: L. L. Leite \& C. H. Saito (org.). Contribuição ao conhecimento ecológico do cerrado; trabalhos selecionados do $3^{\circ}$ Cong. de Ecologia do Brasil, UnB, Brasília-DF.

Cochrane, T. T.; Sánchez, L. G. A.; Porras, J. A. \& Garver, C. L. 1985. Land in Tropical America. V. 3. CIAT/EMBRAPA-CPAC, Cali, Colômbia.

Eiten, G. 1972. The cerrado vegetation of Brazil. The Botanical Review 38(2): 201-341.

Eiten, G. 1975. The vegetation of the Serra do Roncador. Biotropica 7(2): 112-135.

Eiten, G. 1976. Delimitação do conceito de cerrado. Bol. Geogr. Rio de Janeiro 34(249): 131-40.

Eiten, G. 1979. Formas fisionômicas do cerrado. Revista Brasileira de Botânica 2: 139-148.

Eiten, G. 1994. Duas travessias na vegetação do Maranhão. Ed. UnB, Brasília-DF.

Felfili, J. M. 1994. Floristic composition and phytosociology of the gallery forest alongside the Gama stream in Brasília, DF, Brazil. Revista Brasileira de Botânica 17: 1-11.

Felfili, J. M. 1995. Diversity, structure and dynamics of a gallery forest in central Brazil. Vegetatio 117: $1-15$.

IBDF. Instituto Brasileiro de Desenvolvimento Florestal. 1981. Plano de Manejo - Parque Nacional do Araguaia. Min. da Agricultura, BrasíliaDF.

Lorenzi, H.; Souza, H. M.; Medeiros-Costa, J. T.; Cerqueira, L. S. C. \& von Behr, N. 1996. Palmei- 
ras no Brasil. Ed. Plantarum, Nova Odessa-SP.

MMA. Ministério do Meio Ambiente. 1999. Ações prioritárias para a conservação da biodiversidade do Cerrado e Pantanal. MMA/ FUNATURA/Conservation International/Fund. Biodiversitas/UnB. Brasília-DF.

Mori, S. A.; Silva, L. A. M.; Lisboa, G. \& Coradin, L. 1989. Manual de manejo do herbário fanerogâmico. 2. Ed. EMBRAPA-CPLAC, Ilhéus-Ba.

Nascimento, M T. \& Cunha, C. N. 1989. Estrutura e composição florística de um cambarazal no pantanal de Poconé-MT. Acta Botanica Brasilica 3(1): 3-23.

Nimer, E. 1989. Climatologia do Brasil. IBDF, Rio de Janeiro-RJ.

Oliveira-Filho, A. T. 1989. Composição florística e estrutura comunitária da floresta de galeria do Córrego Paciência, Cuiabá-MT. Acta Botanica Brasilica 3: 91-112.

Oliveira-Filho, A. T. \& Furley, P. A. 1990. Monchão, cocuruto, murundu. Ciência Hoje 11(61): 30-37.

Pott, A. \& Pott, V. J. 1994. Plantas do pantanal. EMBRAPA-CPAP, Corumbá-MS.

PRODIAT. Projeto de Desenvolvimento Integrado da Bacia Araguaia-Tocantins. 1984. Fundamentos e estrutura de desenvolvimento integrado do Médio Araguaia Matogrossense. PDI/MAM. Min. do Interior/OEA. Brasília-DF.

RADAMBRASIL. 1981. Levantamento de Recursos Naturais. Ministério das Minas e Energia, 25, Folha SD-22/Goiás.

Ratter, J. A. 1985. Notes on the vegetation close to the sede of the Parque Nacional do Araguaia (IBDF). Royal Botanic Garden, Edinburgh.

Ratter, J. A. 1987. Notes on the vegetation of the Parque Nacional do Araguaia (Brazil). Notes From the Royal Botanic Garden Edinburgh 44(2): 311-342.

Ratter, J. A.; Richards, P. W.; Argent, G. \& Gifford, D. R. 1973. Observations on the vegetation of northeastern Mato Grosso. I. The woody vegetation types of the Xavantina-Cachimbo Expedition area. Philosophical Transactions of the Royal Society of London, Biol. Sciences, 226: 449-492.

Ratter, J. A.; Askew, G. P.; Montgomery, R. F. \& Gifford, D. R. 1978a. Observations on forests of some mesotrophic soils in central Brazil. Revista Brasileira de Botânica 1: 47-58.

Ratter, J. A.; Askew, G. P.; Montgomery, R. F. \& Gifford, D. R. 1978b. Observations on the vegetation of northeastern Mato Grosso II. Forests and soils of the Rio Suiá-Missu area. Proceedings of the Royal Society of London (ser. B) 203: 191208.

Ratter, J. A.; Bridgewater, S.; Atkinson, R. \& Ribeiro, J. F. 1996. Analysis of the floristic composition of the

Brazilian cerrado vegetation II: Comparison of the woody vegetation of 98 areas. Edinburgh Journal of Botany 53(2): 153-180.

Ribeiro, J. F.; Sano, S. M.; Macedo, J.; Silva, J. A. 1983. Os principais tipos físionômicos da região dos cerrados. Boletim de Pesquisas V. 21. EMBRAPA-CPAC, Planaltina-DF.

Ribeiro, J. F. \& Walter, B. M. T. 1998. Fitofisionomias do Bioma Cerrado. Pp. 89-166. In: Sano, S. M. \& Almeida, S. P. (eds.). Cerrado: ambiente e flora. EMBRAPA-CPAC, Planaltina-DF.

Silva Jr., M. C. \& Felfili, J. M. 1996. A vegetação da Estação Ecológica de Águas Emendadas. GDFSEMATEC/IBAMA, Brasília-DF.

Sobrevila, C. \& Bath, P. 1992. Evaluacion Ecologica Rapida; un manual para usuarios de América Latina y el Caribe. The Nature Conservancy, Arlington, USA.

Veloso, H. P.; Rangel-Filho, A. L. R. \& Lima, J. C. A. 1991. Classificação da vegetação brasileira, adaptada a um sistema universal. IBGE, Rio de Janeiro-RJ. 